Article

\title{
Directed Evolution of a Mycobacteriophage
}

\author{
María Cebriá-Mendoza ${ }^{1(\mathbb{D},}$, Rafael Sanjuán ${ }^{1,2}$ and Pilar Domingo-Calap ${ }^{1,2, *(1)}$ \\ 1 Institute for Integrative Systems Biology (I2SysBio), Universitat de València-CSIC, 46980 Paterna, Valencia, \\ Spain; maria.c.cebria@uv.es (M.C.-M.); rafael.sanjuan@uv.es (R.S.) \\ 2 Department of Genetics, Universitat de València, 46100 Burjassot, Valencia, Spain \\ * Correspondence: domingocalap@gmail.com; Tel.: +34-963-543-261
}

Received: 10 April 2019; Accepted: 23 April 2019; Published: 25 April 2019

\begin{abstract}
Bacteriophages represent an alternative strategy to combat pathogenic bacteria. Currently, Mycobacterium tuberculosis infections constitute a major public health problem due to extensive antibiotic resistance in some strains. Using a non-pathogenic species of the same genus as an experimental model, Mycobacterium smegmatis, here we have set up a basic methodology for mycobacteriophage growth and we have explored directed evolution as a tool for increasing phage infectivity and lytic activity. We demonstrate mycobacteriophage adaptation to its host under different conditions. Directed evolution could be used for the development of future phage therapy applications against mycobacteria.
\end{abstract}

Keywords: phage therapy; Mycobacterium smegmatis; mycobacteriophages; directed evolution

\section{Introduction}

Antimicrobial resistance is a major global health concern with a current estimated cost of around 700,000 deaths annually which, if not controlled, could raise up to 10 million deaths by 2050 [1]. Tuberculosis, caused by the bacillus Mycobacterium tuberculosis, is the 9th leading cause of death worldwide, being responsible for 1.3 million deaths in 2016 [2]. Most of this mortality, though, could be prevented with early diagnosis and appropriate treatment. Some $M$. tuberculosis infections are treated successfully with different antibiotics, but the emergence of antibiotic-resistant strains is a growing source of concern. In addition, $M$. tuberculosis can stay in a dormant state inside alveolar macrophages, a population not targeted by most drugs, making it difficult to eradicate the disease [3]. Under this scenario, there is a need to find potential alternative therapies. One possibility is phage therapy, that is, using bacteriophages (phages) to treat bacterial infections. An interesting property of phages is that some can penetrate into macrophages by phagocytosis [4].

Phages are the most abundant biological entity in the planet with an estimated $10^{31}$ total particles. Phages were discovered independently in 1915 and 1917 by Twort and d'Hérelle, respectively. Soon after their discovery, d'Hérelle employed phages to treat dysentery in France and cholera in India. Until the Second World War, phage therapy was considered the only therapeutic tool and the only treatment for bacterial diseases, but the discovery of antibiotics and their introduction in the 1940s replaced phage therapy in most countries, particularly in the West. In contrast, in the former Soviet Union phage therapy was used and is still in practice in countries such as Georgia, Russia, and Poland. Differences in language, in the setting-up of clinical trials between Eastern and Western countries, and the emergence of antibiotics has slowed down the progress of phage therapy in the USA and Western Europe for the past 50 years [5]. Currently, however, the antibiotic resistance crisis has led to a reappraisal of phage therapy worldwide.

The field of phage therapy focuses essentially on virulent phages [6]. In addition to killing bacteria rapidly, phages have some advantages over antibiotics, such as their high host specificity, which reduces the damage to other bacteria and hence avoids dysbiosis. Furthermore, phages multiply at the 
site of infection and only in the presence of their specific bacteria [7]. Based on this, it is expected that phage treatment will require relatively low dosages and treatment frequencies to reach the optimal therapeutic effect [8]. Furthermore, one of the most interesting aspects of phage therapy relates to bacterial resistance, since phages can evolve and overcome resistance [8,9]. Also, directed evolution can help improve phage infectivity, and may be used to reduce resistance emergence rates. Although there are currently no phage therapy products approved as antibacterial drugs for human use in the EU or US, there are ongoing or completed clinical trials [10]. Moreover, the food industry accepts several commercial phage preparations used for biocontrol of bacterial pathogens, which are approved by the FDA, like Listex ${ }^{\mathrm{TM}}$ and ListShield ${ }^{\mathrm{TM}}$ used to protect food from Listeria $[11,12]$.

In this context, we sought to establish proof of concept for the application of phage therapy to mycobacteria. Mycobacteriophages were first isolated in the 1940s using Mycobacterium smegmatis as host and are mostly double-stranded DNA, tailed phages belonging to the Caudovirales group. Currently, there are 10,454 phages described whose host belongs to Mycobacterium genus, of which 1751 are sequenced [13]. Most of these mycobacteriophages belong to the family Siphoviridae (with long, flexible, non-contractile tails) and, in a lower proportion, to the family Myoviridae (with contractile tails) [14]. Mycobacteriophages have provided a wealth of information on the diversity of phages that infect a common bacterial host. In addition, published sequences suggest a mosaic nature for their genomes, with extensive illegitimate recombination and horizontal gene exchange. Mycobacteriophages have been classified in different groups, called clusters, based on sequence similarity [15]. This previous knowledge has provided a variety of tools that can be employed to study mycobacterial genetics and, also, to establish new strategies to control, diagnose and treat diseases caused by mycobacteria [16].

Our main goal here was to demonstrate that evolution under controlled conditions can help us obtain more infective mycobacteriophages. To achieve this aim, we evolved a phage by serial passages under different conditions using M. smegmatis as model host. M. smegmatis is a non-pathogenic bacterium with a faster life cycle than other Mycobacterium species [17], thus offering a good system to explore and set up directed evolution protocols.

\section{Results}

\subsection{Directed Evolution}

We evolved six independent lines (evolution replicates) of M. smegmatis bacteriophage (American Type Culture Collection, ATCC ${ }^{\circledR} 11759-\mathrm{B} 1^{\mathrm{TM}}$ ) in M. smegmatis for 20 serial transfers (passages) in semi-solidified medium, three (Figure $1 \mathrm{~A}-\mathrm{C})$ using a large phage inoculum per passage $\left(10^{5}\right.$ plaque forming units, PFU) and three (Figure 1D-F) using a small phage inoculum ( $\left.10^{2} \mathrm{PFU}\right)$. Independent of passage number, we observed that the phage reached higher titers with a small inoculum $\left(1.28 \pm 0.53 \times 10^{9} \mathrm{PFU} / \mathrm{mL}\right)$ than with a high inoculum treatment $\left(1.94 \pm 0.54 \times 10^{7} \mathrm{PFU} / \mathrm{mL}\right.$; $t$-test using log-transformed titers: $p=0.001$ ). This probably indicates that the large inoculum exhausted the cell population rapidly, whereas a smaller inoculum allowed cells to proliferate for longer, increasing the number of susceptible host cells and, thus, the total amount of viral progeny produced. For the small-inoculum lines, a linear model using the evolution replicate (Figure 1D-F) as a random factor and passage number as a covariate showed that the log-titer increased significantly with passage number $(F=9.071, p=0.004$; Figure 1$)$. In contrast, in phages evolved using a large inoculum size, we could not detect an effect of passage number on log-titer $(F=1.131, p=0.292$; Figure $1 \mathrm{~A}-\mathrm{C})$. 
A
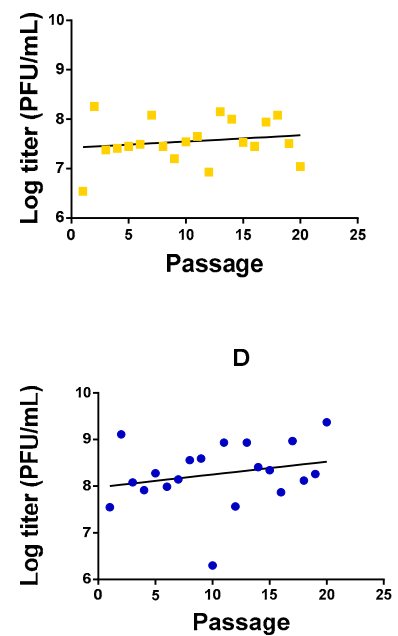

Large inoculum

B

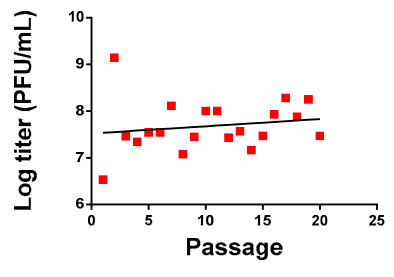

Small inoculum

E

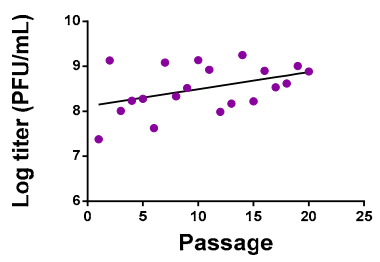

C

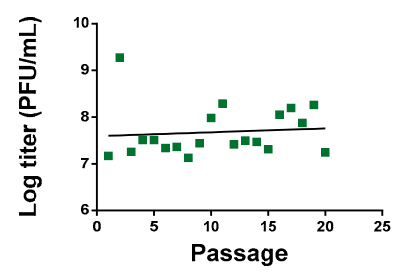

$\mathbf{F}$

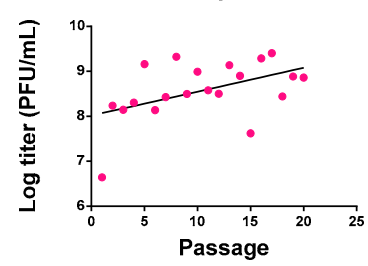

Figure 1. Log-titer reached after each passage of mycobacteriophage evolution. Large inoculum: (A) Yellow, (B) red, (C) green. Small inoculum: (D) Blue, (E) purple, (F) pink. Dots: Experimental points. Line: Linear regression.

\subsection{Analysis of Mycobacteriophage Growth Rate and Stability}

In order to more directly test whether viral fitness changed significantly after 20 passages, we performed standard growth curves in triplicate, in which we compared the founder phage and each of the evolved phages in the same experimental block. Each line was tested using the same inoculum size employed during the evolution experiment. Significant differences between the founder and the evolved lines were found at intermediate and late points ( $t$-tests, $p<0.05$, Figure 2$)$, suggesting an adaptation of all the evolved lines under our different conditions, although less marked for those lines evolved under large inoculum conditions.

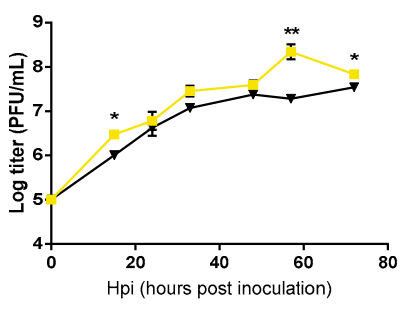

D

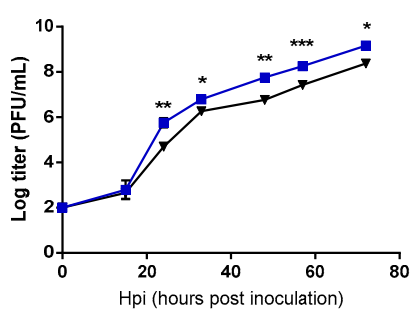

Large inoculum

B

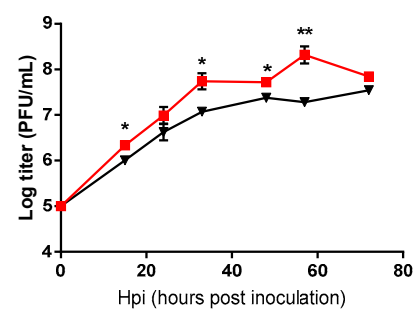

Small inoculum

E

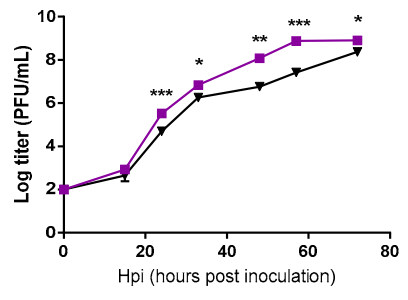

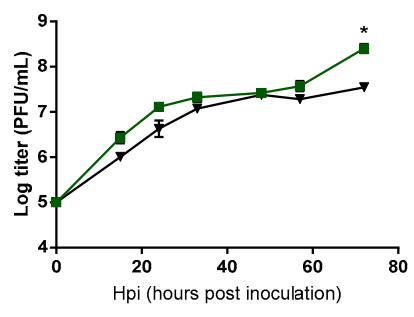

$\mathbf{F}$

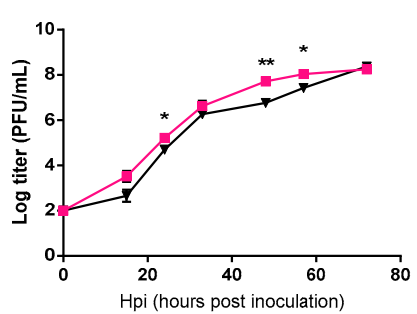

Figure 2. Mycobacteriophages growth curves of the founder and evolved lines. Founder: Black. Large inoculum: (A) Yellow, (B) red, (C) green. Small inoculum: (D) Blue, (E) purple, (F) pink. Dots show the average titer at each time point and error bars indicate the $\operatorname{SEM}(n=3) .{ }^{*}: p<0.05,{ }^{* *}: p<0.005$, $* * *: p<0.0005$. 
In principle, differences in the population growth rate of the phage could be due to the faster infection rate or to the slower degradation rate of the phages. We determined the phage's degradation by measuring the decrease in viral titer as a function of time on the infection medium (in the absence of bacteria). For each lineage (founder and evolved lines), three replicates were done to estimate the degradation rate (Figure 3). Our results showed no differences in degradation rate between the different lines (unpaired $t$-tests, $p>0.05$ ). Hence, the observed acceleration of phage growth was driven by a more rapid infection, which in turn could be due to faster adsorption, faster replication, or increase phage yield per cell.

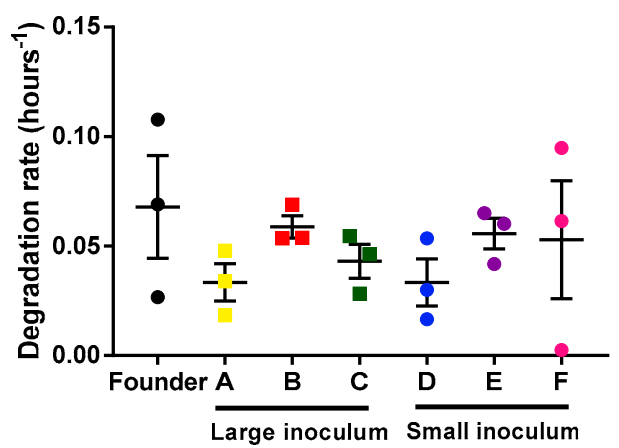

Figure 3. Mycobacteriophages degradation rates of the founder and evolved lines. Founder: Black. Large inoculum: (A) Yellow, (B) red, (C) green. Small inoculum: (D) Blue, (E) purple, (F) pink. Dots show the experimental replicates, and error bars indicate the SEM $(n=3)$.

\subsection{Analysis of Bacterial Lysis Efficiency}

In addition to examining the phage growth rate, we were interested in assessing whether the evolved lines killed M. smegmatis more efficiently than the founder phage. Measurements of bacterial densities at the same time points used above for the phage growth curves were done in triplicate. Again, each phage line was tested using the same inoculum size employed during passages. For large inoculum condition, evolved phages were able to lyse bacteria more efficiently than the founder (nested ANOVA: Founder vs. evolved $p=0.007$, among lines $p=0.082$; Figure 4 ). In contrast, these assays were not capable of detecting differences in lysis activity under small-inoculum conditions (nested ANOVA: Founder vs. evolved $p=0.715$, among lines $p=0.174$; Figure 4) because small inocula did not produce an appreciable change in bacterial density, independent of the phage used. In other words, with large inocula phages were able to reach the majority of bacterial cells growing in the culture dish, whereas, small inocula gave rise to few, isolated plaques which had little effect on overall bacterial counts.

Large inoculum

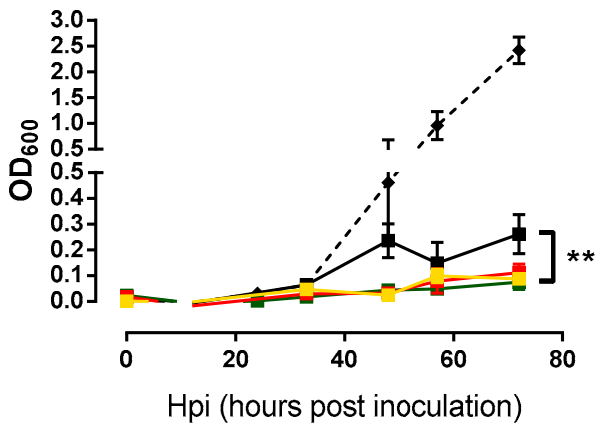

Small inoculum

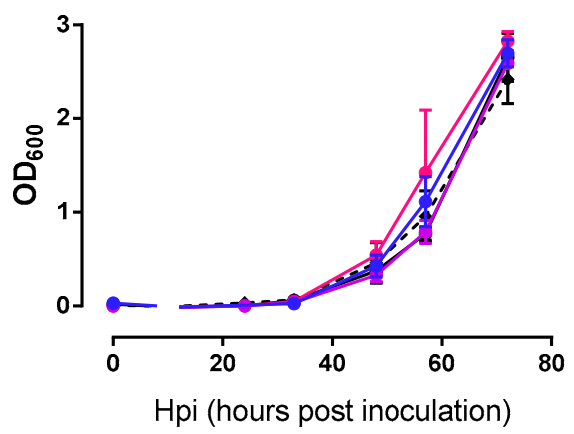

Figure 4. Bacterial growth curves of the founder and evolved lines. Founder: Black. Large inoculum: (A) Yellow, (B) red, (C) green. Small inoculum: (D) Blue, (E) purple, (F) pink. Dots show the average $\mathrm{OD}_{600}$ at each time point and error bars indicate the SEM $(n=3)$. Control without phage infection in dashed line. ${ }^{* *}: p<0.005$. 
To better examine the killing capacity of phage evolved under the small-inoculum regime, we plated all the evolved lines in triplicate to determine differences in the surface area of the plaques using image analysis. Clear differences between the plaque sizes of lines evolved under the small inoculum regime and the founder were detected ( $t$-tests: D: $p<0.001$; E: $p<0.001 ; \mathrm{F}: p=0.009$; Figure 5). A tendency towards increased plaque size was also observed for lines evolved under the large inoculum regime, albeit the effect was less evident than for small-inoculum lines and reached significance only for one of the evolved lines ( $t$-tests: A: $p=0.019$; B: $p=0.408$; $: p=0.134$; Figure 5).
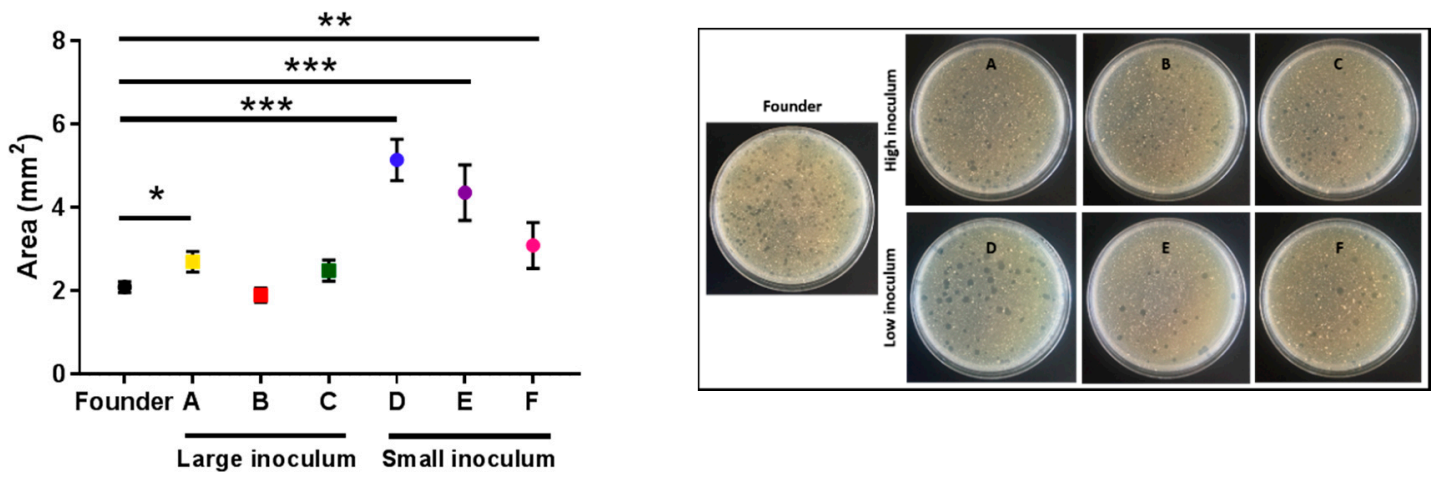

Figure 5. The average area of the plaques of the founder and evolved lines. Founder: Black. Large inoculum: (A) Yellow, (B) red, (C) green. Small inoculum: (D) Blue, (E) purple, (F) pink. Dots show the average area for each line and error bars indicate the $\operatorname{SEM}(n=3){ }^{*}: p<0.05,{ }^{* *}: p<0.005,{ }^{* * *}: p<0.0005$. Right panel: Representative images of the plates for each line.

\section{Discussion}

Directed evolution is a powerful approach for the optimization of different biological processes. The evolution of phage and bacteria has been investigated experimentally in many previous studies [18-22]. However, the experimental evolution of large double-stranded DNA viruses has been less extensively explored, probably because of their lower mutation rates [23], which should slow down evolutionary processes compared to RNA viruses. Yet, some DNA phages have been shown to evolve at rates close to those of RNA phages in the laboratory [18]. We note, though, that there is little or no previous work exploring the evolution of mycobacteriophages under controlled laboratory conditions. Here, we found that phages evolved under our experimental conditions improved fitness as indicated by different analyses. Adaptation has been observed in all the evolved lines (large and small inoculum), demonstrating that the ability to kill bacteria increases after 20 serial passages. In general, higher inoculum sizes achieve higher effective population sizes [19], and increasing the population size typically improves adaptation because this increases allelic diversity and strengthens the efficacy of natural selection relative to random genetic drift [24,25]. However, the dynamics of the host population is also an important factor. If the inoculum is large, the population of host cells can become exhausted rapidly, leaving no resources for further viral replication [26]. This shortens the number of viral generations per passage, potentially slowing adaptation down on an absolute time basis. Clearly, our small-inoculum evolution regime selected for larger plaque sizes than the large-inoculum regime. This increase in plaque size indicates faster spread and more efficient lysis, both of which are interesting properties for phage therapy. Phages evolved under the large-inoculum regime showed increased lysis activity as determined by $\mathrm{OD}_{600}$ measurements, but plaque size measurements revealed little or no improvement in spread ability. Based on this and, since in real treatment settings it is likely that the initial ratio of phage to target bacteria is small, we suggest that directed evolution protocols aimed at increasing the ability of a phage to lyse bacterial populations should be preferably performed under small-inoculum conditions.

Directed evolution can be carried out in liquid or in semi-solidified media. Liquid media combined with shaking allows for more efficient propagation of the phage, whilst semi-solidified media impose spread constraints due to the spatial structure. We believe that the latter approach provides a more 
realistic scenario for phage adaptation and, hence, may select for better phages. Additionally, a liquid culture of mycobacteria is generally difficult because mycolic acids promote cellular aggregation, generating clumps. Adding detergents to the culture can avoid clumps, but these will typically inhibit phage infectivity. For these reasons, we performed our serial transfers in culture dishes instead of liquid-culture tubes. Phage diffusion is limited in semi-solidified media and is dependent on virion morphology and size. In most cases, phage progeny from one cell will infect neighbor cells only, imposing selection pressures that probably differ from those of well-mixed populations. Mycobacteriophages should be able to increase fitness in many different ways, including improvement in the attachment to cell receptors, increased burst size, reduced lysis time, or faster replication, among others, and the outcome may depend on medium viscosity. A better understanding of the molecular mechanisms responsible for adaptation would be obtained by sequencing the evolved lines. Yet, this can be difficult due to the relatively large genome of mycobacteriophages compared to other viruses and the large number of genes with unknown functions.

Bacteria can evolve phage resistance fast by different mechanisms, including loss of the receptor or activation of the CRISPR system $[27,28]$. Antagonistic coevolution between phage and bacteria implies ongoing selection of host resistance and resistance breaking, which results in changes in phage and host genomes across evolutionary time [29]. Previous works have shown that infection efficiency improves in comparison with a wild-type phage when the coevolution process is performed using preadapted phages (phages which have been subjected to evolutionary passages) [19,20]. This might be an alternative strategy for achieving resistance breaking and for obtaining in the laboratory a phage population capable of preventing the emergence of resistant bacteria during treatment.

Our work provides proof of concept for the use of directed evolution in a mycobacteriophage. Despite the fact that phages are highly specific to their hosts, some mycobacteriophages can infect both M. tuberculosis and M. smegmatis [30]. Thus, it is possible that our results are applicable to M. tuberculosis. However, additional experiments should be done to explore this possibility.

\section{Materials and Methods}

\subsection{Bacterial Strains and Culture Conditions}

We used M. smegmatis $\Delta 1366$ (M. smegmatis) [31], kindly provided by Dr. José Luis García (CSIC). This strain is a clone of $\mathrm{mc}^{2} 155$ which has the MSMEG_1366 gene deleted (ABC transporter, ATP-binding protein) and has a plasmid encoding kanamycin resistance and Venus fluorescent protein. M. smegmatis was grown in Lysogeny Broth (LB) medium at $37^{\circ} \mathrm{C}$ with shaking $(250 \mathrm{rpm})$ in the case of liquid media [16]. LB was supplemented with kanamycin $20 \mu \mathrm{g} \cdot \mathrm{mL}^{-1}$, as well as with $5 \mathrm{mM} \mathrm{CaCl}_{2}$ to improve phage growth. For growing bacteria in semi-solidified media, 1.5\% of agar was added to LB and kanamycin was omitted. In order to preserve bacteria, glycerol $20 \%(v / v)$ was added to bacterial cultures, which were stored at $-70^{\circ} \mathrm{C}$. A stock of non-evolved bacteria was done in a first step. For this purpose, a culture of $M$. smegmatis in supplemented LB was incubated until $\mathrm{OD}_{600}=0.3$ was reached. The culture was divided into $50 \mathrm{~mL}$ tubes and chilled on ice. These tubes were centrifuged at $2000 \times g$ for $15 \mathrm{~min}$ at $4{ }^{\circ} \mathrm{C}$. The supernatant was discarded and the pellet was resuspended in ca. $30 \mathrm{~mL}$ of LB with $15 \%$ of glycerol to obtain a $40 \times$ concentrated stock. The culture was split into $250 \mu \mathrm{L}$ aliquots that were flash-frozen in liquid nitrogen and stored at $-70^{\circ} \mathrm{C}$.

\subsection{Mycobacteriophage}

The M. smegmatis bacteriophage was obtained from ATCC (reference ATCC ${ }^{\circledR} 11759 \mathrm{~B} 1^{\mathrm{TM}}$ ). Phage buffer (Tris- $\mathrm{HCl} \mathrm{pH} \mathrm{7.5,} 10 \mathrm{mM} \mathrm{MgSO}_{4}, 5 \mathrm{mM} \mathrm{CaCl}_{2}$ and $68.5 \mathrm{mM} \mathrm{NaCl}$ [13] was used for phage dilutions, phage recovery and phage storage. For phage propagation, $M$. smegmatis was grown to an $\mathrm{OD}_{600}$ of 0.3 in supplemented LB. We mixed $100 \mu \mathrm{L}$ of $M$. smegmatis culture with $100 \mu \mathrm{L}$ of phage. This mix was incubated without shaking for $15 \mathrm{~min}$ at room temperature to allow for phage adsorption. The infection was inoculated in $2 \mathrm{~mL}$ of supplemented LB and was incubated for $48 \mathrm{~h}$ at $37^{\circ} \mathrm{C}$. After that, cultures were 
centrifuged at $16,000 \times g$ for $1 \mathrm{~min}$, the pellet was discarded and the supernatant was aliquoted and stored at $-70{ }^{\circ} \mathrm{C}$. For phage titration, serial dilutions of each aliquot were prepared and $100 \mu \mathrm{L}$ of these dilutions were employed to infect $10^{7} \mathrm{CFU}$ of $M$. smegmatis. Titration was done onto LB plates with top agar (LB with $0.7 \%$ agar) and plates were incubated for $40 \mathrm{~h}$ at $37^{\circ} \mathrm{C}$. After this, plaques were counted to determine titers.

\subsection{Evolution}

The indicated amount of PFU was used to inoculate $10^{7} \mathrm{CFU}$ of non-evolved M. smegmatis obtained from our frozen stock (see above) at an initial $\mathrm{OD}_{600}$ of 0.3 . Two different conditions were tested: Large inoculum ( $\left.10^{5} \mathrm{PFU}\right)$ and small inoculum $\left(10^{2} \mathrm{PFU}\right)$. Twenty serial passages from plate to plate were performed, controlling the initial inoculum $\left(10^{5} \mathrm{PFU}\right.$ or $\left.10^{2} \mathrm{PFU}\right)$ for each replicate at each passage. For this, after each passage, phages were titrated by the plaque assay. For each condition, three evolution replicates (lines) were established. Inoculations were carried with $100 \mu \mathrm{L}$ of phage suspension onto LB plates with top agar and incubated for $40 \mathrm{~h}$ at $37^{\circ} \mathrm{C}$. To collect phages, $5 \mathrm{~mL}$ of phage buffer was added to the plates and incubated for $2 \mathrm{~h}$ at $37^{\circ} \mathrm{C}$ [32]. Then, $2 \mathrm{~mL}$ of this phage buffer were collected and cells were removed by centrifugation $(16,000 \times g$ for $1 \mathrm{~min})$. The supernatant was aliquoted and stored at $-70{ }^{\circ} \mathrm{C}$. One aliquot of each condition was used for the next passage.

\subsection{Growth Curves}

Infections were started with $10^{5}$ PFUs in the case of phages evolved using a high inoculum size and with $10^{2}$ PFUs in the case of phages evolved with a low inoculum size, that is, under the same conditions used for evolution. The founder phage was included in all assays. For each time tested, we performed three replicates per line. Infections were performed as above onto LB plates with top agar and incubated at $37^{\circ} \mathrm{C}$ for different times ( 0 hpi, 15 hpi, 24 hpi, 33 hpi, 46 hpi, 57 hpi and 72 hpi). Then, plates were flooded with $5 \mathrm{~mL}$ of phage buffer and incubated for $2 \mathrm{~h}$ at $37^{\circ} \mathrm{C}$. The buffer $(2 \mathrm{~mL})$ was collected and $\mathrm{OD}_{600}$ measures were done for each replicate at each time point. Afterward, samples were centrifuged $(16,000 \times g$ for $1 \mathrm{~min})$ to remove cells, and supernatants were aliquoted, stored at $-70{ }^{\circ} \mathrm{C}$ and titrated.

\subsection{Mycobacteriophage Degradation Rates}

Founder and evolved lines were used to estimate the mycobacteriophage degradation rate. For this, $10^{4}$ PFUs were added to $3.5 \mathrm{~mL}$ of top agar in the absence of bacteria and were plated in semi-solidified agar plates and titrated at $0 \mathrm{hpi}, 24 \mathrm{hpi}, 48 \mathrm{hpi}$, and $72 \mathrm{hpi}$, as described previously.

\subsection{Plaque Sizes}

Estimates of plaque sizes for the evolved and ancestral lines were done in triplicate. Plating was done by carrying out plaque assays with an estimated 100 PFUs. Plaque size was determined at 72 hpi and was calculated by image analysis using ImageJ software (National Institutes of Health, Bethesda, MD, USA).

\section{Conclusions}

The present work is a step forward in the use of directed evolution as an optimization tool in mycobacteriophages. We have shown that evolved phages exhibit improved lytic activity compared with the founder phage under our experimental conditions. Our results might help in the development of future treatments against pathogenic and multi-resistant Mycobacterium tuberculosis strains, and suggest phage therapy as a potential alternative to the conventional antibiotics.

Author Contributions: Conceptualization, R.S. and P.D.-C.; Data curation, R.S. and P.D.-C.; Formal analysis, R.S. and P.D.-C.; Funding acquisition, R.S.; Investigation, M.C.-M. and P.D.-C.; Methodology, M.C.-M. and P.D.-C.; Resources, P.D.-C.; Supervision, P.D.-C.; Validation, P.D.-C.; Visualization, P.D.-C.; Writing-original draft, M.C.-M.; Writing-review \& editing, R.S. and P.D.-C. 
Funding: This work was funded by grant BFU2017-84762-R from the Spanish Ministerio de Ciencia, Innovación y Universidades (MCIU) and grant 724519-Vis-à-vis from the European Research Council (ERC) to R.S. P.D.-C. was recipient of a Juan de la Cierva Incorporación contract from MCIU.

Acknowledgments: We thank José Luis García López for the bacterium and María Durán-Moreno for technical assistance.

Conflicts of Interest: The authors declare no conflict of interest.

\section{References}

1. Górski, A.; Miedzybrodzki, R.; Weber-Dabrowska, B.; Fortuna, W.; Letkiewicz, S.; Rogóz, P.; Jończyk-Matysiak, E.; Dabrowska, K.; Majewska, J.; Borysowski, J. Phage Therapy: Combating Infections with Potential for Evolving from Merely a Treatment for Complications to Targeting Diseases. Front. Microbiol. 2016, 7, 1-9. [CrossRef] [PubMed]

2. World Health Organization. Global Tuberculosis Report 2017. Available online: https://www.who.int/tb/ publications/global_report/en/ (accessed on 24 April 2019).

3. Samaddar, S.; Grewal, R.K.; Sinha, S.; Ghosh, S.; Roy, S.; Das Gupta, S.K. Dynamics of Mycobacteriophage-Mycobacterial Host Interaction: Evidence for Secondary Mechanisms for Host Lethality. Appl. Environ. Microbiol. 2016, 82, 124-133. [CrossRef] [PubMed]

4. Jończyk-Matysiak, E.; Weber-Dąbrowska, B.; Owczarek, B.; Międzybrodzki, R.; Łusiak-Szelchowska, M.; Łodej, N.; Górski, A. Phage-Phagocyte Interactions and Their Implications for Phage Application as Therapeutics. Viruses 2017, 9, 150. [CrossRef] [PubMed]

5. Domingo-Calap, P.; Georgel, P.; Bahram, S. Back to the Future: Bacteriophages as Promising Therapeutic Tools. HLA 2016, 87, 133-140. [CrossRef] [PubMed]

6. Housby, J.N.; Mann, N.H. Phage Therapy. Drug Discov. Today 2009, 14, 536-540. [CrossRef]

7. Weber-Dabrowska, B.; Jończyk-Matysiak, E.; Zaczek, M.; Łobocka, M.; Łusiak-Szelachowska, M.; Górski, A. Bacteriophage Procurement for Therapeutic Purposes. Front Microbiol. 2016, 1-14. [CrossRef] [PubMed]

8. Nilsson, A.S. Phage Therapy-Constraints and Possibilities. Ups. J. Med. Sci. 2014, 119, 192-198. [CrossRef]

9. Ul Haq, I.; Chaudhry, W.N.; Akhtar, M.N.; Andleeb, S.; Qadri, I. Bacteriophages and Their Implications on Future Biotechnology: A Review. Virol. J. 2012, 9, 9. [CrossRef]

10. Kingwell, K. Bacteriophage Therapies Re-Enter Clinical Trials. Nat. Rev. Drug Discov. 2015, 14, 515-516. [CrossRef]

11. Lin, D.M.; Koskella, B.; Lin, H.C. Phage Therapy: An Alternative to Antibiotics in the Age of Multi-Drug Resistance. World J. Gastrointest. Pharmacol. Ther. 2017, 8, 162-173. [CrossRef] [PubMed]

12. Gray, J.A.; Chandry, P.S.; Kaur, M.; Kocharunchitt, C.; Bowman, J.P.; Fox, E.M. Novel Biocontrol Methods for Listeria Monocytogenes Biofilms in Food Production Facilities. Front. Microbiol. 2018, 9, 1-12. [CrossRef]

13. The Actinobacteriophage Database. Available online: http://phagesdb.org/ (accessed on 24 April 2019).

14. Lima-Junior, J.D.; Viana-Niero, C.; Conde Oliveira, D.V.; Machado, G.E.; Rabello, M.C.D.S.; Martins-Junior, J.; Martins, L.F.; Digiampietri, L.A.; Da Silva, A.M.; Setubal, J.C.; et al. Characterization of Mycobacteria and Mycobacteriophages Isolated from Compost at the São Paulo Zoo Park Foundation in Brazil and Creation of the New Mycobacteriophage Cluster U. BMC Microbiol. 2016, 16, 1-15. [CrossRef] [PubMed]

15. Hatfull, G.F. Molecular Genetics of Mycobacteriophages. Microbiol. Spectr. 2014, 2. [CrossRef] [PubMed]

16. Jacobs-Sera, D.; Marinelli, L.J.; Bowman, C.; Broussard, G.W.; Guerrero Bustamante, C.; Boyle, M.M.; Petrova, Z.O.; Dedrick, R.M.; Pope, W.H.; Modlin, R.L.; et al. On the Nature of Mycobacteriophage Diversity and Host Preference. Virology 2012, 434, 187-201. [CrossRef] [PubMed]

17. Klann, A.G.; Belanger, A.E.; Abanes-de Mello, A.; Lee, J.Y.; Hatfull, G.F. Characterization of the DnaG Locus in Mycobacterium smegmatis Reveals Linkage of DNA Replication and Cell Division. J. Bacteriol. 1998, 180, $65-72$.

18. Domingo-Calap, P.; Cuevas, J.M.; Sanjuán, R. The Fitness Effects of Random Mutations in Single-Stranded DNA and RNA Bacteriophages. PLoS Genet. 2009, 5, 1-7. [CrossRef]

19. Domingo-Calap, P.; Sanjuán, R. Experimental evolution of RNA versus DNA viruses. Evolution (NY) 2011, 65, 2987-2994. [CrossRef]

20. Pal, C.; Maciá, M.D.; Oliver, A.; Schachar, I.; Buckling, A. Coevolution with Viruses Drives the Evolution of Bacterial Mutation Rates. Nature 2007, 450, 1079-1981. [CrossRef] 
21. Betts, A.; Gray, C.; Zelek, M.; MacLean, R.C.; King, K.C. High Parasite Diversity Accelerates Host Adaptation and Diversification. Science 2018, 360, 907-911. [CrossRef]

22. Wichman, H.A.; Badgett, M.R.; Scott, L.A.; Boulianne, C.M.; Bull, J.J. Different Trajectories of Parallel Evolution During Viral Adaptation. Science 1999, 285, 422-424. [CrossRef]

23. Sanjuán, R.; Domingo-Calap, P. Mechanisms of Viral Mutation. Cell. Mol. Life Sci. 2016, 73, 4433-4448. [CrossRef]

24. Miralles, R.; Gerrish, P.J.; Moya, A.; Elena, S.F. Clonal Interference and the Evolution of RNA Viruses. Science 1999, 285, 1745-1747. [CrossRef] [PubMed]

25. Arjan, G.J.; de Visser, M.; Zeyl, C.W.; Gerrish, P.J.; Blanchard, J.L.; Lenski, R.E. Diminishing Returns from Mutation Supply Rate in Asexual Populations. Science 1999, 283, 404-406. [CrossRef]

26. Kick, B.; Hensler, S.; Praetorius, F.; Dietz, H.; Weuster-Botz, D. Specific Growth Rate and Multiplicity of Infection Affect High-Cell-Density Fermentation with Bacteriophage M13 for ssDNA Production. Biotechnol. Bioeng. 2017, 114, 777-784. [CrossRef]

27. Sun, C.L.; Barrangou, R.; Thomas, B.C.; Horvath, P.; Fremaux, C.; Banfield, J.F. Phage Mutations in Response to CRISPR Diversification in a Bacterial Population. Environ. Microbiol. 2012, 15, 463-470. [CrossRef]

28. Deveau, H.; Barrangou, R.; Garneau, J.E.; Labonté, J.; Fremaux, C.; Boyaval, P.; Romero, D.A.; Horvath, P.; Moineau, S. Phage Response to CRISPR-Encoded Resistance in Streptococcus Thermophilus. J. Bacteriol. 2008, 190, 1390-1400. [CrossRef]

29. Scanlan, P.D.; Buckling, A.; Hall, A.R. Experimental Evolution and Bacterial Resistance: (Co)Evolutionary Costs and Trade-Offs as Opportunities in Phage Therapy Research. Bacteriophage 2015, 5, e1050153. [CrossRef]

30. Broxmeyer, L.; Sosnowska, D.; Miltner, E.; Chacón, O.; Wagner, D.; McGarvey, J.; Barletta, R.G.; Bermudez, L.E. Killing of Mycobacterium Avium and Mycobacterium Tuberculosis by a Mycobacteriophage Delivered by a Nonvirulent Mycobacterium: A Model for Phage Therapy of Intracellular Bacterial Pathogens. J. Infect. Dis. 2002, 186, 1155-1160. [CrossRef] [PubMed]

31. García-Fernández, J.; Papavinasasundaram, K.; Galán, B.; Sassetti, C.M.; García, J.L. Unravelling the Pleiotropic Role of the MceG ATPase in Mycobacterium Smegmatis. Environ. Microbiol. 2017, 19, 2564-2576. [CrossRef]

32. Piuri, M.; Rondón, L.; Urdániz, E.; Hatfull, G.F. Generation of Affinity-Tagged Fluoromycobacteriophages by Mixed Assembly of Phage Capsids. Appl. Environ. Microbiol. 2013, 79, 5608-5615. [CrossRef] [PubMed] 